\title{
Pediatric Typical Vs. Atypical Celiac Disease: Correlation of Duodenal Histology With Tissue Transglutaminase Levels
}

\author{
Aleksandra Boskovic ${ }^{\mathrm{a}, \mathrm{b}}$, Ivana Kitic ${ }^{\mathrm{a}}$, Dragan Prokic ${ }^{\mathrm{a}}$, Ivica Stankovic ${ }^{\mathrm{a}}$
}

\begin{abstract}
Background: Both the clinical presentation and the degree of mucosal damage in coeliac disease vary greatly. In view of conflicting information as to whether the mode of presentation correlates with the degree of villous atrophy, we reviewed a 103 pediatric patient with coeliac disease. This study also aimed to determine the correlation of anti tTG level and the degree of mucosal damage in typical and atypical cases.
\end{abstract}

Methods: The medical records of patients with newly diagnosed CD during the period of 2006 - 2010 were retrospectively reviewed.

Results: A total of 103 patients fulfilled the established CD diagnostic criteria (mean age: 6.6 years; mediana: 5 years). A typical CD presentation was observed for 66/103 (64.1\%) children vs atypical 37/103 (35.9\%). The levels of tTG antibody were correlated significantly with Marsh types in the entire population by Spearman rank correlation $(\mathrm{r}=0.661, \mathrm{P}<0.0001)$, and separately for typical $(\mathrm{r}=0.633, \mathrm{P}<0.001)$ and atypical $(\mathrm{r}=0.574, \mathrm{P}<0.0001)$ groups. Histopathological evaluation of intestinal biopsies revealed total or subtotal VA in 44 patients $(66.6 \%)$ in the typical group, and 24 patients $(64.8 \%)$ in the atypical group. Partial VA was observed in 5 patients $(7.5 \%)$ in the typical group and $1(2.7 \%)$ patients in atypical group. There was no correlation of mode of presentation (typical and atypical) with the degree of villous atrophy by a nonparametric Mann-Whitney $\mathrm{U}$ test $\mathrm{Z}=-1.437, \mathrm{P}=0.151$.

Conclusions: There is a positive correlation between tTG antibody serum level and duodenal histopathology in typical as in atypical pediatric $\mathrm{CD}$. The degree of villous atrophy did not correlate with the mode of presentation, indicating that factors other than the degree of villous atrophy must account for typical simptoms in coeliac disease.

Manuscript accepted for publication October 4, 2012

${ }^{\mathrm{a}}$ Department of Gastroenterology, Mother and Child Health Care Institute, Belgrade, Serbia

${ }^{\mathrm{b}}$ Corresponding author: Aleksandra Boskovic, Department of

Gastroenterology, Mother and Child Health Care Institute, Belgrade,

Serbia. Email: aleksandra.bos@hotmail.com

doi: http://dx.doi.org/10.4021/ijcp57w
Keywords: Child; Atypical celiac disease; Anti-tissue transglutaminase level

\section{Introduction}

In recent years there has been increasing recognition that the pattern of presentation of coeliac disease may be changing. The classic sprue syndrome with diarrhoea and weight loss may be less common than the more subtle presentations of coeliac disease. As a result, the diagnosis of this treatable condition is often delayed or missed. Recent serologic screening tests allow non-invasive screening to identify most patients with the disease and can be applied in patients with even subtle symptoms indicative of coeliac disease. Both benign and malignant complications of coeliac disease can be avoided by early diagnosis and a strict compliance with a gluten free diet. Human anti-tissue transglutaminase (tTG) antibodies are used widely in CD screening. A high correlation between tTG titer and duodenal histopathology has also been reported, but non of these studies refered to atypical coeliac disease. This study also aimed to determine does the mode of presentation correlate with the degree of villous atrophy.

\section{Materials and Methods}

\section{Patients}

Pediatric CD patients were recorded retrospectively from 2006 to 2010 at Mother and Child Health Care Institute, Belgrade, tertiary center in Serbia. Patients were referred from primary care settings or from other medical specialties for diagnosis and follow-up. Subjects were referred for evaluation of clinical complaints suggestive of $\mathrm{CD}$, had positive family history or belonged to some high-risk group for CD.

None of the patients included had a previous diagnosis of $\mathrm{CD}$ before they attended at our clinic and were on a free diet (gluten containing diet).

The clinical spectrum was divided into two categories 


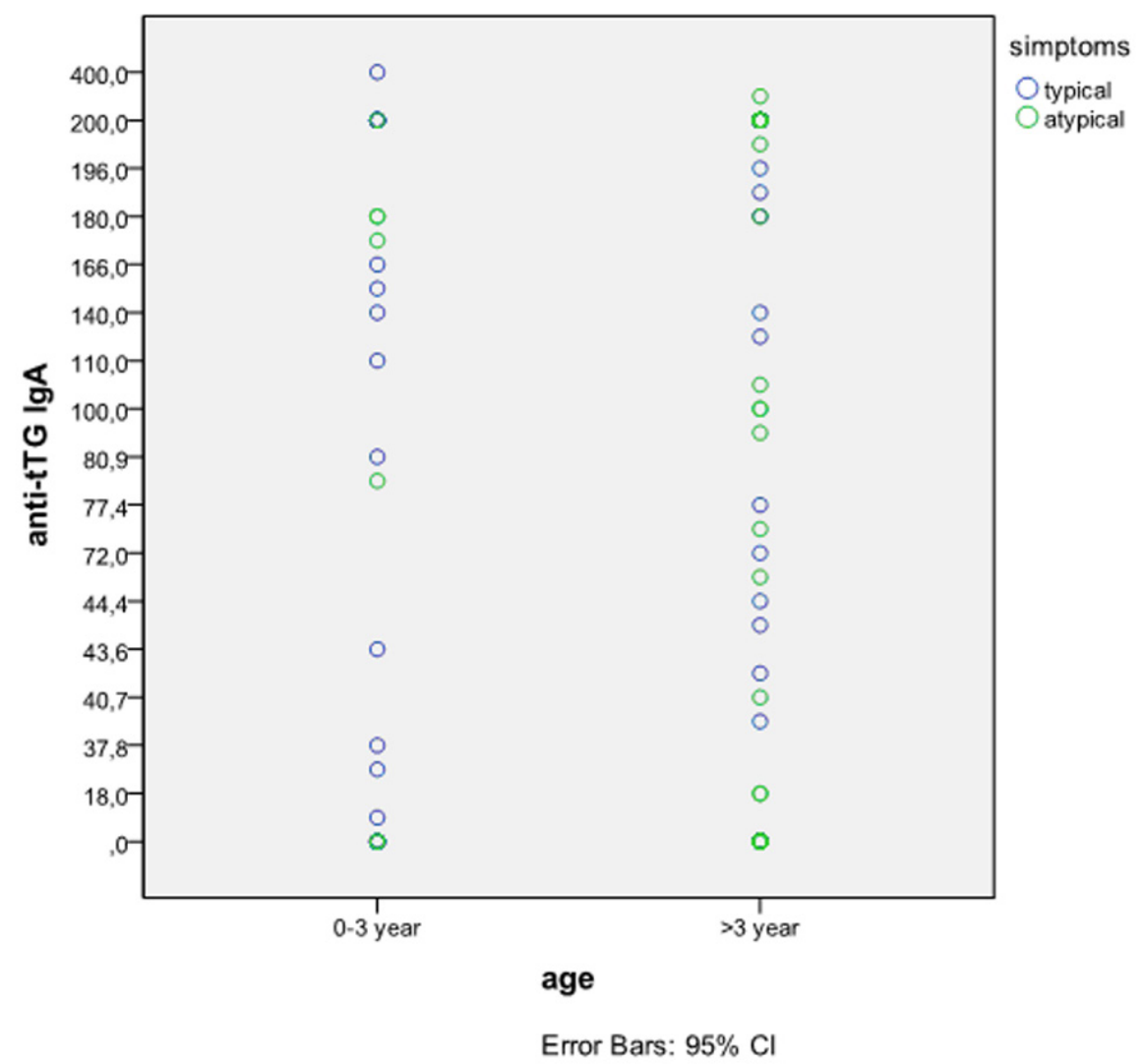

Figure 1. Serum tTG antibody level vs patient age. There was no age-related differences in tTG antibody titers. Pearson Chi-Square 0.242, $\mathrm{P}=7.96$.

according to the main symptoms that led to diagnosis: (1) typical or classical, clinical malabsorption, chronic diarrhea or failure to thrive (children $\leq 2$ years); and (2) atypical or oligosymptomatic, abdominal pain, iron deficiency anemia, chronic hypertransaminasemia, growth failure (children $\geq 3$ years) or screening of risk groups or familial study.

\section{Serology and human leukocyte antigen (HLA) genotype}

Quantitative detection of human IgA class tTG antibody was measured with an enzyme-linked immunosorbent assay kit (Orgentec,GmbH,Mainz-Germany). The manufacturer reference ranges for positive results were values $>10 \mathrm{IU} / \mathrm{mL}$. A cut-off level $>100 \mathrm{IU} / \mathrm{mL}$ tTG antibody was considered strongly positive for additional evaluations. IgA level was determined together with $\mathrm{tTG}$ antibodies and IgA deficiency patients were not included.

All CD patients were typed for HLA-DQ2 (DQA $1 * 0501$ and DQB1*0201 alleles) and DQ8 (DQA1*03 and DQB1*0302 alleles) by polymerase chain reaction.

\section{Histopathology}

Biopsies from the distal duodenum (minimum of four forceps biopsies) were obtained by upper gastrointestinal endoscopy.
The pathologist experienced with $\mathrm{CD}$ diagnosis reviewed the histopathological specimens and classified them according to Marsh's criteria as modified by Oberhuber et al. Type 3 specimens (any degree of villous atrophy) were considered characteristic of CD. Marsh 1 and 2 lesions were considered nonspecific, but consistent with $\mathrm{CD}$ diagnosis with positive serology and HLA DQ2 and DQ8 compatibility. Patients with March 0, positive serology and compatible HLA were considered as "latent" or "potential" CD. Three patients had anaphylactic type of $\mathrm{CD}$ with negative serology. Those cases with Marsh 3 lesions and negative serology were evaluated for an alternative diagnosis that could explain the histological abnormalities.

\section{Statistical analysis}

Data were analyzed using SPSS version 13.0. Categorical variables were expressed as numbers and percentages and quantitative variables as mean $\pm \mathrm{SD}$. Categorical variables were analyzed by cross-tabulations using a $\chi^{2}$ test with a continuity correction test when necessary. A non-parametric Mann-Whitney U test was used when the groups values deviated from a normal curve. Associations between quantitative variables were assessed by Pearson correlation test or Spearman rank correlation test. $\mathrm{P}<0.05$ was selected to re- 


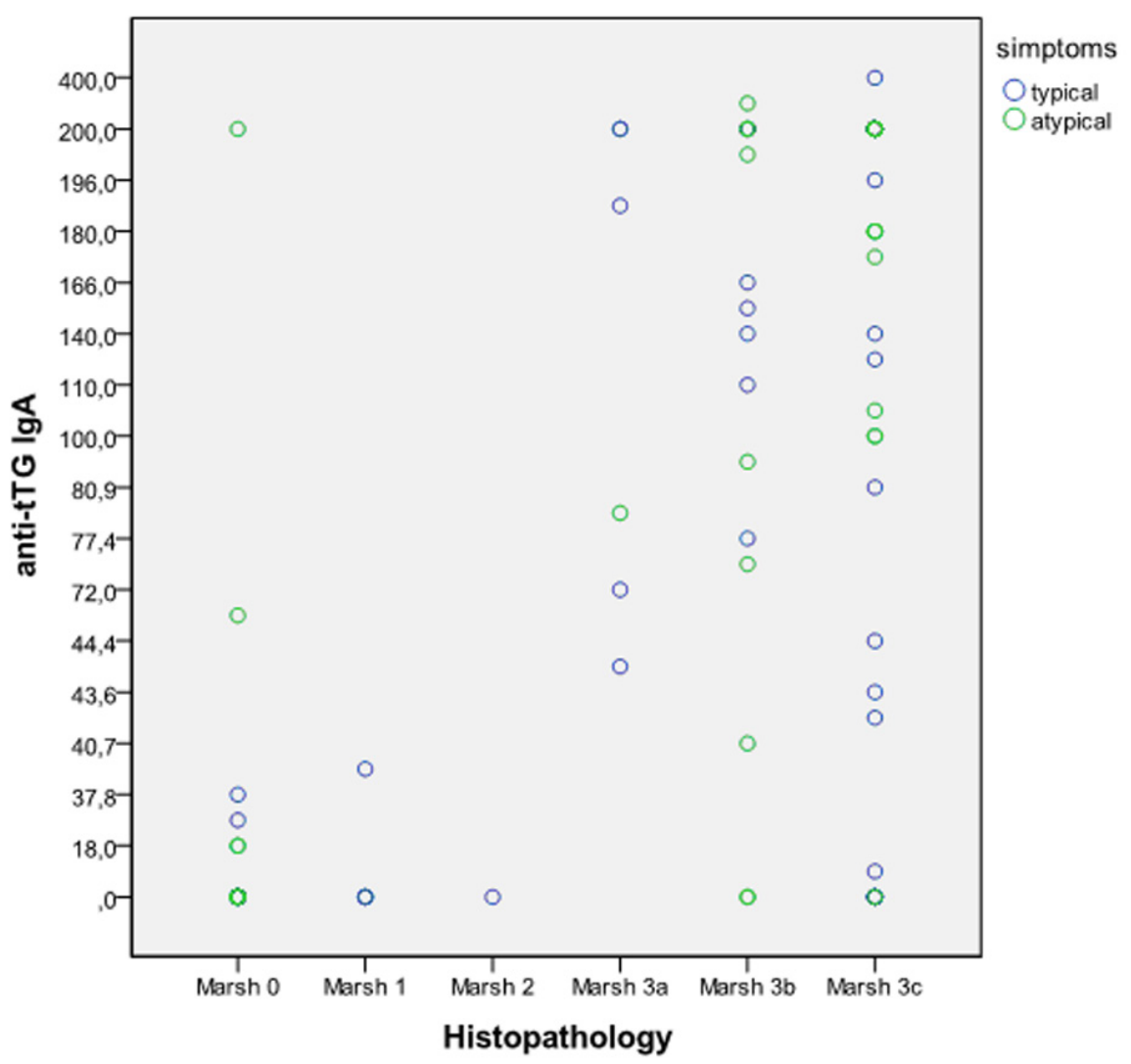

Figure 2. Serum tTG antibody levels vs Marsh classification. Spearman rank correlation; typical $(r=$ $0.633, P<0.001)$ vs atypical $(r=0.574, P<0.0001)$.

ject the null hypothesis by two-tailed tests.

\section{Results}

\section{Patient characteristics}

A total of 103 patients fulfilled the established CD diagnostic criteria (mean age: 6.6 years; range: 0 - 18years; mediana: 5 years). A typical CD presentation was observed for $66 / 103$ (64.1\%) children vs atypical 37/103 (35.9\%).Female/male ratio was $1.27: 1$ typical vs atipycal $1.64: 1$. This difference is considered to be not statistically significant (Chi square $=$ $0.970 \mathrm{P}=0.325$ typical vs atypical Chi square $=2.189, \mathrm{P}=$ $0.139)$.The patients had been divided into two groups: age 0 -3 years, and $>3$ years. Atypical presentation had extremely statistically significant difference between those two groups (Chi square $=14.297 \mathrm{P}=0.0002$ ), while typical had no statistically significant difference.

There was no age-related differences in tTG antibody titers (Pearson Chi-Square 0.242 P = 7.96) (Fig. 1). Total or subtotal VA was present in 44 patients $(66.6 \%)$ in the typical group, and 24 patients (64.8\%) in the atypical group (P $<0.0001)$.

\section{Human recombinant IgA tTG antibodies and Marsh type}

The levels of tTG antibody were correlated significantly with Marsh types in the entire population by Spearman rank correlation $(\mathrm{r}=0.661, \mathrm{P}<0.0001)$, and separately for typical $(\mathrm{r}=0.633, \mathrm{P}<0.001)$ and atypical $(\mathrm{r}=0.574, \mathrm{P}<0.0001)$ groups (Fig. 2). Mean tTG antibody levels showed a progressive increase that was associated with higher Marsh types. Mean tTG antibody level and March 3 enteropathy for typical CD was $140.53 \pm 88.77 \mathrm{IU} / \mathrm{mL}$ vs. atypical $140.66 \pm$ $73.53 \mathrm{IU} / \mathrm{mL}$.

There were no atypical CD patients with March 1 and 2 level enteropathy. Positive serology and March 0 had 12 (32.4\%) atypical CD patients that belong to potential CD with HLA-DQ2 or DQ8 compatibility and $11(16.6 \%)$ typical CD patients. Only one of them in atypical group had anti tTG level $>100 \mathrm{IU} / \mathrm{mL}$. Among atypical CD patients from family screening $6 / 9$ had tTG level $>100 \mathrm{IU} / \mathrm{mL}$ and enteropathy March 3 level.

Histopathological evaluation of intestinal biopsies revealed total or subtotal VA in 44 patients $(66.6 \%)$ in the typical group, and 24 patients $(64.8 \%)$ in the atypical group. Partial VA was observed in 5 patients $(7.5 \%)$ in the typical group and $1(2.7 \%)$ patients in atypical group. There was 


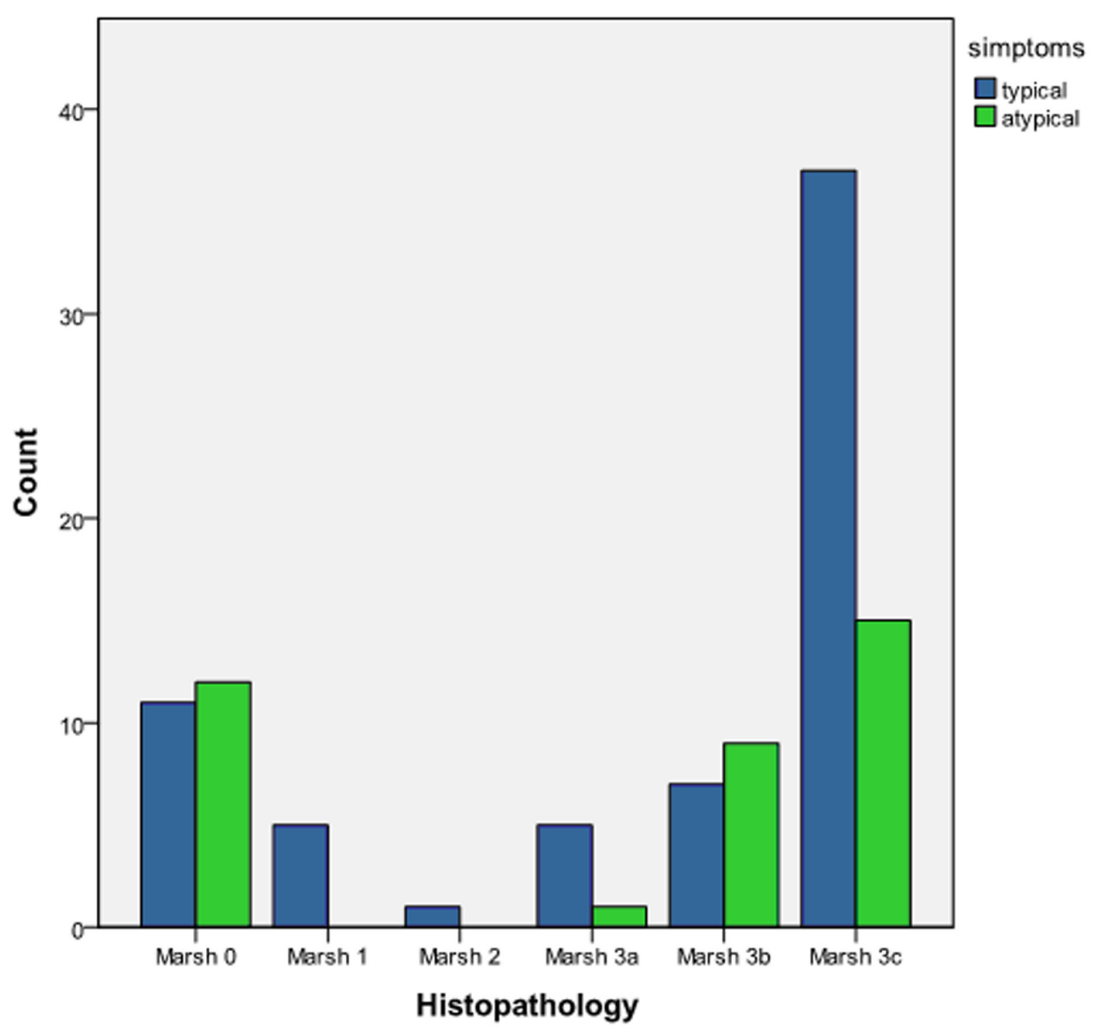

Figure 3. Histopathological differences between typical and atypical CD according to Marsh classification. A non-parametric Mann-Whitney $U$ test $Z=\urcorner-1.437, P=0.151$.

no correlation of mode of presentation (typical and atypical) with the degree of villous atrophy by a non-parametric Mann-Whitney $\mathrm{U}$ test $\mathrm{Z}=\neg-1,437, \mathrm{P}=0.151$ (Fig. 3).

\section{Discussion}

Celiac disease (CD) is recognized as one of the most common and important autoimmune gastrointestinal disorders affecting children. There is evidence that a diagnosis of CD during childhood improves health outcomes. The increasing prevalence of $\mathrm{CD}$ is due to increased awareness of the wide range of extraintestinal symptoms associated with $\mathrm{CD}$.

A positive correlation between tTG antibody serum level and duodenal histopathology has been described previously for pediatric and adult CD [1-3]. However, previous similarly designed studies did not analyzed the correlation between tTG antibody serum level and histopathology in atypical CD cases. Furthermore, we also describe differences between typical and atypical pediatric $\mathrm{CD}$ patients.

The pathogenesis of gluten-induced small-intestinal changes and atrophy is not understood fully [4]. It is considered to be T-cell mediated. However, recent in vitro studies $[5,6]$, and a study that reported anti-tTG2 IgA deposits in a morphologically normal jejunum before systemic detection of tTG antibody predicted overt CD with atrophy [7], sug- gest a pathogenic role for antibodies.

In our study the level of tTG antibody was correlated significantly with Marsh types in the entire population by Spearman rank correlation $(\mathrm{r}=0.661, \mathrm{P}<0.0001)$, and separately for typical $(\mathrm{r}=0.633, \mathrm{P}<0.001)$ and atypical $(\mathrm{r}=$ $0.574, \mathrm{P}<0.0001$ ) group. Fabiani et al [8] showed significantly lower levels of tTG in patients with mild enteropathy than in those with more severe enteropathy. Hansson et al [9] in a study conducted in 57 children with biopsy-verified $\mathrm{CD}$, showed serum tTG levels to be significantly increased in patients with mucosal atrophy compared with patients with partial or subtotal villous atrophy. In a previous series referring to adult patients [10], tTG levels were also found to be strongly correlated with the histologic degree of mucosal damage, as in our pediatric patients with pediatric CD. None of this studies showed separately the correlation for typical and atypical CD. We showed that there is no diference between clinical presentation of CD in correlation of tTG antibody level and severity of duodenal lession. The limit of our work is represented by the small number of patients with atypical $\mathrm{CD}$.

The choice of an upper cut-off limit of tTG antibody to predict accurately CD or Marsh type 3 lesions may depend on the commercial kit used for tTG IgA ELISA. On the basis of previous experience $[1,2,11]$ we considered $100 \mathrm{IU} / \mathrm{mL}$ as the cut-off that resulted in the highest predictive value. 
Our series established CD diagnosis based on clinical judgment and expertise. In our study there was age-related differences in clinical presentation of CD. Atypical presentation was predominant in older group ( $>3$ years) of patients. Rodrigo et al found that pediatric CD has clear differences when compared to adult $\mathrm{CD}$, with classic forms predominating in the former, who also display a higher occurrence of positive serology and villous atrophy, and less diagnostic delay. In contrast, atypical forms predominate in the adult, with a lower occurrence of positive serology and milder histological forms [12]. Schreiber et al found that because of the lack of gastrointestinal symptoms, the diagnosis of atypical celiac disease is often made only at an advanced stage and advanced age [13].

DQ2 or DQ8 were found positive in patients with type 0 disease, who showed positive tTG in all cases, exept one that had anaphylactic type of CD.Therefore, according to other studies [14-17] patients with type 0 disease can be considered in our experience as "potential CD." It is known that patients without histologic damage but with immunologic abnormalities need to undergo repeated biopsies under normal gluten consumption to show a progression toward the typical mucosal changes [14-17].Our patients with type 0 disease will require careful follow-up. These patients will undergo multiple biopsies after normal gluten consumption if they are still found tTG-positive, because the first normal biopsy could represent a missed biopsy resulting from the patchy nature of the lesion in the early stages [18-22]. Patients with type 1 and 2 disease, and all HLA antigens compatible with $\mathrm{CD}$ were also submitted to a gluten-free diet with clinical recovery. All of our patients with mucosal atrophy started a gluten-free diet, with complete resolution of the symptoms.

Histopathological evaluation of intestinal biopsies revealed total or subtotal VA in 44 patients $(66.6 \%)$ in the typical group, and 24 patients $(64.8 \%)$ in the atypical group. Partial VA was observed in 5 patients $(7.5 \%)$ in the typical group and $1(2.7 \%)$ patients in atypical group. There was no correlation of mode of presentation (typical and atypical) with the degree of villous atrophy by a non-parametric Mann-Whitney $\mathrm{U}$ test $\mathrm{Z}=-1.437, \mathrm{P}=0.151$.

Among our patients the degree of villous atrophy in duodenal biopsies did not correlate with the mode of presentation by a non-parametric Mann-Whitney $U$ test , indicating that factors other than the degree of villous atrophy must account for typical simptoms in coeliac disease.

Brara et al in the cohort study, consisted of 499 adults,found among patients that the degree of villous atrophy in duodenal biopsies did not correlate with the mode of presentation [23]. On the other hand Dinler et al found among 87 children that total/subtotal villous atrophy was significantly higher in the typical group than in the atypical group [24].

In our study among atypical $\mathrm{CD}$ patients from family screening 6/9 (66\%) had tTG level > $100 \mathrm{IU} / \mathrm{mL}$ and enter- opathy March 3. All of our respondents with positive antibody findings had no symptoms that could indicate celiac disease. After establishing the diagnosis of celiac disease in children, it should be mentioned that testing must be done with the first relatives. This would, along with further diagnostic testing discover a significant number of asymptomatic patients and atypical forms of celiac disease.

\section{Conclusion}

We showed a positive correlation between tTG antibody serum level and duodenal histopathology in typical as in atypical pediatric CD. Among our patients the degree of villous atrophy in duodenal biopsies did not correlate with the mode of presentation, indicating that factors other than the degree of villous atrophy must account for typical simptoms in coeliac disease. More awareness regarding the atypical presentation of $\mathrm{CD}$ could be the key step in identifying asymptomatic patients.

\section{References}

1. Donaldson MR, Book LS, Leiferman KM, Zone JJ, Neuhausen SL. Strongly positive tissue transglutaminase antibodies are associated with Marsh 3 histopathology in adult and pediatric celiac disease. J Clin Gastroenterol. 2008;42(3):256-260.

2. Donaldson MR, Firth SD, Wimpee H, Leiferman KM, Zone JJ, Horsley W, O'Gorman MA, et al. Correlation of duodenal histology with tissue transglutaminase and endomysial antibody levels in pediatric celiac disease. Clin Gastroenterol Hepatol. 2007;5(5):567-573.

3. Collin P, Kaukinen K, Vogelsang H, Korponay-Szabo I, Sommer R, Schreier E, Volta U, et al. Antiendomysial and antihuman recombinant tissue transglutaminase antibodies in the diagnosis of coeliac disease: a biopsyproven European multicentre study. Eur J Gastroenterol Hepatol. 2005; 17(1):85-91.

4. Schuppan D. Current concepts of celiac disease pathogenesis. Gastroenterology. 2000;119(1):234-242.

5. Esposito C, Paparo F, Caputo I, Rossi M, Maglio M, Sblattero D, Not T, et al. Anti-tissue transglutaminase antibodies from coeliac patients inhibit transglutaminase activity both in vitro and in situ. Gut. 2002;51(2):177181.

6. Freitag T, Schulze-Koops H, Niedobitek G, Melino G, Schuppan D. The role of the immune response against tissue transglutaminase in the pathogenesis of coeliac disease. Autoimmun Rev. 2004;3(2):13-20.

7. Korponay-Szabo IR, Halttunen T, Szalai Z, Laurila K, Kiraly R, Kovacs JB, Fesus L, et al. In vivo targeting of intestinal and extraintestinal transglutaminase 2 by coeliac autoantibodies. Gut. 2004;53(5):641-648. 
8. Fabiani E, Catassi C. The serum IgA class anti-tissue transglutaminase antibodies in the diagnosis and follow up of coeliac disease. Results of an international multicentre study. International Working Group on Eu-tTG. Eur J Gastroenterol Hepatol. 2001;13(6):659-665.

9. Hansson T, Dahlbom I, Rogberg S, Dannaeus A, Hopfl P, Gut H, Kraaz W, et al. Recombinant human tissue transglutaminase for diagnosis and follow-up of childhood coeliac disease. Pediatr Res. 2002;51(6):700-705.

10. Tursi A, Brandimarte G, Giorgetti GM. Prevalence of antitissue transglutaminase antibodies in different degrees of intestinal damage in celiac disease. J Clin Gastroenterol. 2003;36(3):219-221.

11. Barker CC, Mitton C, Jevon G, Mock T. Can tissue transglutaminase antibody titers replace small-bowel biopsy to diagnose celiac disease in select pediatric populations? Pediatrics. 2005;115(5):1341-1346.

12. Rodrigo-Saez L, Fuentes-Alvarez D, Perez-Martinez I, Alvarez-Mieres N, Nino-Garcia P, de-Francisco-Garcia R, Riestra-Menendez S, et al. Differences between pediatric and adult celiac disease. Rev Esp Enferm Dig. 2011;103(5):238-244.

13. Schreiber FS, Ziob T, Vieth M, Elsbernd H. [Atypical celiac disease in a patient with type 1 diabetes mellitus and Hashimoto's thyreoiditis]. Dtsch Med Wochenschr. 2011;136(3):82-85.

14. Holmes GK. Potential and latent coeliac disease. Eur J Gastroenterol Hepatol. 2001;13(9):1057-1060.

15. Arranz E, Bode J, Kingstone K, Ferguson A. Intestinal antibody pattern of coeliac disease: association with gamma/delta $\mathrm{T}$ cell receptor expression by intraepithelial lymphocytes, and other indices of potential coeliac disease. Gut. 1994;35(4):476-482.

16. Hill ID, Bhatnagar S, Cameron DJ, De Rosa S, Maki
M, Russell GJ, Troncone R. Celiac disease: Working Group Report of the First World Congress of Pediatric Gastroenterology, Hepatology, and Nutrition. J Pediatr Gastroenterol Nutr. 2002;35 Suppl 2:S78-88.

17. Picarelli A, di Tola M, Sabbatella L, Mastracchio A, Trecca A, Gabrielli F, di Cello T, et al. Identification of a new coeliac disease subgroup: antiendomysial and anti-transglutaminase antibodies of $\operatorname{IgG}$ class in the absence of selective IgA deficiency. J Intern Med. 2001;249(2):181-188.

18. Marsh MN, Crowe PT. Morphology of the mucosal lesion in gluten sensitivity. Baillieres Clin Gastroenterol. 1995;9(2):273-293.

19. Troncone R, Greco L, Mayer M, Paparo F, Caputo N, Micillo M, Mugione P, et al. Latent and potential coeliac disease. Acta Paediatr Suppl. 1996;412:10-14.

20. Ferguson A, Arranz E, O’Mahony S. Clinical and pathological spectrum of coeliac disease--active, silent, latent, potential. Gut. 1993;34(2):150-151.

21. Collin P, Helin H, Maki M, Hallstrom O, Karvonen AL. Follow-up of patients positive in reticulin and gliadin antibody tests with normal small-bowel biopsy findings. Scand J Gastroenterol. 1993;28(7):595-598.

22. Maki M, Collin P. Coeliac disease. Lancet. 1997;349(9067):1755-1759.

23. Brar P, Kwon GY, Egbuna, II, Holleran S, Ramakrishnan $\mathrm{R}$, Bhagat G, Green PH. Lack of correlation of degree of villous atrophy with severity of clinical presentation of coeliac disease. Dig Liver Dis. 2007;39(1):26-29; discussion 30-22.

24. Dinler G, Atalay E, Kalayci AG. Celiac disease in 87 children with typical and atypical symptoms in Black Sea region of Turkey. World J Pediatr. 2009;5(4):282286. 